\title{
Motivation Strategy Using Gamification
}

\author{
Tae Matsumoto \\ Kanto Gakuin University, Yokohama, Japan \\ Email: matsumoto_4017@yahoo.co.jp
}

Received 31 May 2016; accepted 10 July 2016; published 13 July 2016

Copyright (C) 2016 by author and Scientific Research Publishing Inc.

This work is licensed under the Creative Commons Attribution International License (CC BY). http://creativecommons.org/licenses/by/4.0/

(c) (i) Open Access

\begin{abstract}
The number of university students' dropouts is increasing rapidly these days in Japan. One of the possible causes is some kinds of problems relating to economic reasons. The other reason, there is a marked decline in the students' scholastic performance. They are not able to keep up with class work at school. Our recent studies have focused on e-Learning support methods using the Gamification. It is one form of the above game-informed education. So far, we have seen that the student can use the Internet pleasantly and very interestingly. In this paper, we propose the flipped classroom design method using the Gamification. The flipped classroom is at the center of this discussion. It is an inverted version of the traditional learning model. It is a new pedagogical method. It is becoming increasingly well known around the University education in Japan. This concept has been put to use in several different fields, one such field being education. It is a type of blended learning. In order to discuss the pros and cons of gamification of education, the authors conducted an experiment and questionnaire using e-Learning with gamification elements for English as foreign language education. The results of this study particularly highlighted the importance of well-designed tutorial, task, interface and feedback for the effective game-based e-Learning. Therefore, "flipped classroom based on gamification" is helpful in improving learners' understanding level and motivation.
\end{abstract}

\section{Keywords}

E-Learning, Gamification, Motivation, Flipped Classroom

\section{Introduction}

The number of university students' dropouts is increasing rapidly these days in Japan. There is a marked decline in the students' scholastic performance. They are not able to keep up with class work at school. Over the past few years, a considerable number of studies have been made on remedial education. Remedial education is rapidly increasing (Matsumoto, 2012; Matsumoto, 2014). Remedial education, refers to classes intended to also known as developmental education, basic skills education, compensatory education of new university students. 
Our recent studies have focused on e-Learning (Remedial education) support methods using the Gamification. It is one form of the above game-informed education. It is considered that effective gamification and game-based language by and large share the following elements: a clear and concise tutorial, learner-driven tasks, a wellorganized interface, and motivation-stimulating and immediate feedback (Sykes \& Reinhardt, 2012). So far, we have seen that the student can using the Internet pleasantly and very interestingly. Recent year have seen a renewal of interest in the flipped classroom. It is an inverted version of the traditional learning model. The flipped classrooms are able to remodel large lecture classes into active-Learning. Active-Learning is a key aspect of the flipped classroom. In flipped classrooms, students watch videos and online lectures outside of class, and valuable class time is used to solve problems and apply concepts. It is becoming increasingly well known around the University education in Japan. It is a type of blended learning. Blended learning is which is an approach to integrate different learning environments. In this paper, we focus on the flipped classroom support methods using the Gamification. In order to discuss the pros and cons of gamification of education, the authors conducted an experiment and questionnaire using e-Learning with gamification elements for English as foreign language education. The proposed method based on the gamification could overcome the already mentioned. But it is necessary to consider uses of gamification according to the varying needs of learners.

\section{E-Leanring}

E-Learning stands for electronic learning and is the application of electronic media and/or information and communication technologies to education. One of the most frequently mentioned positive aspect of e-Learning is that it can overcome problems related to space and time. This is to say, with electronic devices (e.g., a personal computer) and, in many cases, internet connection, learners can conduct wherever they are and whenever they want. However, as a downside, it has also been pointed out that e-Learning will not be a productive learning method for learners with weak motivation and self-regulation ability.

\subsection{Self-Determination Theory}

There are many theories regarding how and why students are motivated. The human behavior is induced by needs stimulated by drive and incentive. The motive is classified as intrinsic motive and extrinsic motive. SelfDetermination $\rightarrow$ Intrinsic motivation $\rightarrow$ More effective learning, supported the validity of the sequence model (Dickinson, 1995).

\subsection{Interactive System}

Recently, innovation of the Internet allows us to publish and share various. For example, we contents using CGM (contents generating media) such as blog, wiki (Wikipedia) and SNS (Social Networking Service). In addition, Instagram and Line (application). Ever since, Word of mouth on the web are becoming popular. The novelty induces curiosity significant for human motivation by word of mouth online. The epistemic curiosity is significant element in intrinsic motivation.

\subsection{Instructional Design}

There are many theories and models for instructional design (ID) (Keller, 2008; Keller, 2010). It is a systemic approach to designing effective learning, teaching and training. ID has captured attention through e-Learning. The goal of ID is to make instruction more effective, efficient, and appealing.

\subsection{Support Methods}

We introduce existing e-Learning support methods. Existing E-learning support methods are roughly classified into three types as follows. First type is blended learning, which is an approach to integrate different learning environments. Second type is mentor support. Mentor is a supervisor who promotes and advocates each e-learning student. Third type is PSI that stands for Personalized System of Instruction. This is a mastery learning model which improves the mastery of each e-learning student about his/her pre-specified set of classes. There are merits and demerits to existing e-learning support methods. So other new e-Learning support methods are necessary. 


\subsection{The Flipped Classroom}

It is becoming increasingly well known around the University education in Japan.The flipped classroom is an inverted version of the traditional learning model. In the flipped classroom, instructors typically assign recorded video lectures as homework, and use class time for active learning exercises and direct engagement with students. It is a type of blended learning. And yet, the needs of video contents for flipped classroom and Massive Open Online Courses (MOOCs) have been increasing rapidly. However, blended learning, which combines online and face-to-face elements, yielded better. For example, absent students appreciated the opportunity to see what they missed. But, so did students who hadn't missed class. Online learning can continue outside the classroom. This downside particularly applies to independent e-Leaning (e.g., uses Videos, or computer programs for self-learning). As more fully described below, by adding self-learning facilitating elements to the current e-learning system, gamification can provide a solution to this problem.

\section{New E-Learning Support Methods}

\subsection{Gamification}

We would like to introduce existing e-Learning support methods using the Gamification, Gamification is one form of the above game-informed education. Gamification is a new coinage. Gamification is not equal to games. A game is structured play, usually for enjoyment. Gamification is a strategy for influencing and motivating the behavior of people. We use of game design elements in non-game contexts. It means an implementation and use of game design elements and techniques. According to Zichermann and Cunningham, gamification is an application of game dynamism and system to real-life problem-solving (Zichermann \& Cunningham, 2011).

\subsubsection{Taske}

Learners have to achieve certain levels of requirement in order to receive adequate grades, be promoted to senior classes and/or pass examinations. Task completion is considered to be a useful method to accomplish the abovementioned learning objectives. A task of game-based the flipped classroom is more learner-drive.

\subsubsection{Interface}

Interface in this context not only represents smooth and accurate responses to the inputs in computer-assisted learning (e.g., the ability to control our avatar's actions without any problems), but also stands for the organization of the learning process in both cyber-net and face-to-face learning contexts (cf., Sykes \& Reinhardt, 2012).

\subsubsection{Feedback}

The importance of feedback has also been acknowledged in our research. Feedback in e-learning education often means error (e.g., correction aiming for the accurate comprehension and production of the target language).

\subsection{Gamification Design for the E-Learning}

Gamification projects focus on framework design in e-Learning. The theory of Gamification Design for the eLearning (GDE) from the field of Education is a guide for instructional designers to help them create course content that is appropriate for a diverse group of learners. GDE is that courses should be designed so that students can demonstrate-Learning in a variety of ways.

\section{Research Objectives}

The Ministry of Education, Culture, Sports, Science and Technology of Japan has recently started to change English education in Japan to a more communication-based education aiming to foster practical English abilities. Schools and companies put strong emphasis on scores of entrance examinations and English tests for enrolment and employment.Not studies have ever tried to the flipped classroom. Flipped classroom studies recently have started to pay attention to the effectiveness of gamification of e-learning, this research field is still in its infancy. Hence, this study decided to broaden the field. In particular, this study focused on the effectiveness of e-Learning with gamification elements in Flipped classroom. This study conducted an experiment and questionnaire 
using e-Learning with gamification elements for FL (foreign language) education in order to illustrate how gamification elements or their absence cause motivation and demotivation in the learning experience.

\section{Method}

\subsection{Participants}

\subsubsection{Remedial Education}

A total of 77 Japanese English as FL learners were sampled in this study (As shown in Table 1). The participated to all students in the the first year of high school students located in kansai. The participants had not used the Surala (e.g., "Surala is Gamification Design for the e-Learning”) for the English class. The survey period was one week. All of the participants agreed to participate in this study and signed a consent from. The questionnaire survey was conducted in June 2012 [4]. Data collection was accomplished through a designed written questionnaire during the study week.

\subsubsection{The Flipped Classroom}

A total of 60 Japanese English as FL learners were sampled in this study. All of them are the first year of high school students. The sample consisted of 46 males and 14 females (Table 2). The school is located in kansai. They are not good at English. The survey period was two months. All of the participants agreed to participate in this study and signed a consent from. The questionnaire survey was conducted in February 2014. Before the survey, the participants had used GDE for the English class which was held twice a week from April to December of 2013.

\subsection{E-Learning Material}

Super Rapid Accumulation of Lasting Abilities (E-leaning contents) was used as the e-learning material. The gamification elements of E-leaning contents are the following.

\subsubsection{Learning Process Visualization}

In the home screen of E-leaning contents, learners can check the number of tasks they have finished so far (blue circle), a number of to-do tasks in a given week (yellow circle), the history of their task completion (blue circle) and their achievement ranking compared to other learners (green circle). This visualization of the learning process is first expected to help learners in self-setting their goal in LL. In addition, learners can also regulate their learning using this information. As stated above, providing learners multiple choices for task completion is one of the most significant characteristics of learner-driven LL.

\subsubsection{Interactive Characters}

When learners start studying, they will first receive lectures from several in-game characters, and then deal with the language task (s) related to the contents which they have learned in the lecture. The characters first explain some vocabulary and structures of English. Following this, learners will be provided the actual use of the target vocabulary and structures. When learners complete their task, the characters give them a compliment (e.g., "congratulations for leveling up!”) so that learners can explicitly realize their skill acquisition in the relevant domain.

Table 1. Experimental l subjects (77students).

\begin{tabular}{ccc}
\hline & Man & Woman \\
\hline First year of high school & 17 & 60 \\
\hline Table 2. Experimental l subjects (60 students). & & \\
\hline & Man & Woman \\
\hline First year of high school & 46 & 14 \\
\hline
\end{tabular}


Table 3. Pre/post test uses GED.

\begin{tabular}{ccc}
\hline & Get better score & To go down score \\
\hline First school (Table 1) & $86.8 \%$ & $13.3 \%$ \\
Second school (Table 2) & $74.5 \%$ & $18.2 \%$ \\
\hline
\end{tabular}

\subsubsection{Custom-Made Feedback}

Using each learner's error data, E-leaning contents diagnoses the weak point(s) of the learner and provides feedback to them. For instance, if a learner makes many mistakes in the section of the past perfect, E-leaning contents judges that this learner's weak point is rooted in the lack of knowledge in the past tense. Then, E-leaning contents shows this diagnosis to the learner and recommends him/her to review the relevant units again. In addition to this feedback, E-leaning contents repeatedly asks questions related to the learner's weak point until the learner masters the target structures. This feedback is expected to reduce the dropout rate caused by the setbacks in the LL process. Figure 5 is a sample picture of actual learning using E-leaning contents.

\subsection{Questionnaire}

The goal of these open-ended interviews and pre/post-tests was to obtain detailed data on students. An openended questionnaire was employed in this study. The open-ended method was taken because very few studies made mentions of pros and cons of e-learning with gamification elements. The following questions were used in this study: "What do you think about GDE?” and “Do you think GDE was good for your English learning?

\subsection{Data Analysis}

After the data collection, this study first eliminated invalid responses such as blanks and "nothing special". At the end, a total of 68 descriptive responses were retained for data analysis and 68 students were given a pre/post test. Next, this study eliminated invalid responses such as blanks and "nothing special" opinions from free description questionnaire answer sentences. At the end, a total of 58 (44males and 14 females) descriptive responses were retained for data analysis and 58 students were given a pre/post test.

\section{Result and Discussion}

The number of questions for achievement test is pre and post. Table 3 shows the results of achievement pre/post test score. It is quite obvious that the "sulara" e-Learning contetn study improvement.

\section{Conclusion}

The findings of this study can be boiled down to the following statement: in order to conduct fruitful the flipped classroom with gamification elements in the field of LL, it was also mentioned earlier that all of the data came from the first year of high school, it is important to consider the characteristics of the learners as well as pedagogies' ideal level of achievement. In order to obtain a more general representation of Japanese high school students, additional data from different schools, preferably of varying academic levels, should be examined. I can employ the results shown in this study to help adjudicate between theoretical positions on the important factors associated with the gamification. The findings of this study will be an informative source for future studies. The limitation of this study lies in its narrow focus. To deal with this problem, the authors are currently preparing for larger sample size studies aiming to provide concrete evidence to the findings and recommendations of this study. But it is necessary to consider uses of gamification according to the varying needs of learners.

\section{References}

Dickinson, L. (1995). Autonomy and Motivation: A Literature Review. System, 23, 165-174. http://dx.doi.org/10.1016/0346-251X(95)00005-5

Keller, J. M. (2008). First Principles of Motivation to Learn and e3-Learning. Distance Education, 29, 175-185. http://dx.doi.org/10.1080/01587910802154970 
Keller, J. M. (2010). Motivational Design for Learning and Performance: The ARCS Model Approach. Springer. http://dx.doi.org/10.1007/978-1-4419-1250-3

Matsumoto, T. (2012). Possibility of e-Learning by Using Gamification. Japanese Society for Information and Systems in Education, 27, 35-40.

Matsumoto, T. (2014). Different Point of Based Social Game and Gamification. The Journal of Information Science and Technology Association, 64, 481-484.

Sykes, J., \& Reinhardt, J. (2012). Language at Play: Digital Games in Second and Foreign Language Teaching and Learning. New York: Pearson.

Zichermann, G., \& Cunningham, C. (2011). Gamification by Design: Implementing Game Mechanics in Web and Mobile Apps. Sebastopol, CA: O’Reilly Media.

\section{Submit or recommend next manuscript to SCIRP and we will provide best service for you:}

Accepting pre-submission inquiries through Email, Facebook, Linkedin, Twitter, etc A wide selection of journals (inclusive of 9 subjects, more than 200 journals)

Providing a 24-hour high-quality service

User-friendly online submission system

Fair and swift peer-review system

Efficient typesetting and proofreading procedure

Display of the result of downloads and visits, as well as the number of cited articles

Maximum dissemination of your research work

Submit your manuscript at: http://papersubmission.scirp.org/ 